\title{
3. Regionalism and Cultural Identity: Putting the Pacific back into the plan
}

\section{Elise Huffer}

\author{
We treasure the diversity of the Pacific and seek a future in which its \\ cultures, traditions and religious beliefs are valued, honoured and \\ developed. \\ - Forum Leaders' vision, expressed in the Auckland Declaration of April \\ 2004
}

In April 2004, the Pacific Islands Forum leaders issued the Auckland Declaration, paving the way for the design of a Pacific Plan for Strengthening Regional Cooperation and Integration. The plan is part of a process of reform officially launched through the endorsement at the 2003 Forum Leaders' meeting of New Zealand Prime Minister, Helen Clark's, request, as chair of the forum, to review the 'forum's role, functions and Secretariat'. An Eminent Persons' Group (EPG) was set up and, after region-wide consultations, it drafted a review, entitled Pacific Cooperation: Views of the Region, in which it recommended the endorsement by Pacific leaders of a Pacific Plan 'to create stronger and deeper links between the countries of the region' (EPG 2004: 21).

The plan was thus envisioned as a way to strengthen the region and particularly to help it adapt to encroaching global conditions, in accordance with the EPG's stern assessment that: 'The bottom line is that future inter-country relationships will need to be closer and more mutually supportive if the region is to avoid decline and international marginalisation.' Leaders in the region are no doubt concerned about the problems their countries are facing, such as growing unemployment, poverty, crime, lack of resources to provide basic services and opportunities to their peoples, as well as tensions between national and local governance norms and institutions. There is a genuine conviction that the region is having difficulty coping with global pressures and changes. As the EPG review states, 'Modernisation and globalisation have brought wonders to our shores but they have also exposed the vulnerability of our small island developing states. They have threatened our family and community bonds and values, weakened our ability to live off the land and sea, and upset our harmony with the natural environment. Nevertheless we shall stand strong to preserve our region, our heritage and the best aspects of our traditions, and enhance them for the benefit of future generations.'

The plan was conceptualised by the EPG as the tool that would ensure that the leaders' Pacific vision could be translated into reality via intensified regional 
cooperation. But in its understanding of the purpose of regionalism the EPG emphasised the need for a 'focus on people'. In particular, it affirmed that ' $\mathrm{t}$ ] ogether we shall work to ensure that this is a region where people matter more than anything else, and where every person feels loved, needed and able to enjoy a free, responsible and worthwhile life'. As a guide to ensuring that this focus on people was upheld, the EPG noted a series of areas that it considered required 'immediate attention' at the regional level. The first area listed was 'cultural identity'.

One of the fundamental aspects of contemporary Pacific culture and cultural identity is its ideal of a focus on people, relationships, on caring and sharing networks, and on working together for the betterment of all. Furthermore, cultural identity is a bond that brings Pacific Island countries and peoples together. As the EPG states, 'Our cultures link us with other Pacific peoples, and with our sea, land and ancestors.' Unfortunately, at present, the plan endorsed by the Forum Leaders in 2005 has little to say about culture. Cultural issues are viewed only as strategic objectives under two of the four goals of the plan, namely, sustainable development and good governance, but not as the foundation for further regional integration.

This paper argues that Pacific Island countries have traditionally sought to make cultural identity the foundation of regionalism and that it is in their best interest to continue to build on this approach if regionalism is to have any meaning for the peoples of the Pacific Islands and if it is to become an effective tool for the betterment of governance and development in the Pacific. The paper begins with a brief overview of the current draft plan, its process, main objectives, and its inadequacy in addressing cultural identity. It then discusses the past role of culture in establishing a foundation for regionalism and the difficulties of integrating culture in regionalism, before suggesting ways in which cultural identity can be promoted as a platform for furthering regionalism.

\section{The plan}

The Pacific Plan is a blueprint for paving the way from the existing form of regional cooperation towards other more integrated forms of regionalism. The authors of the plan are known as the Task Force. They were supported by the Forum Secretariat and based their approach on an ADB report written by Roman Grynberg and others. They identified three 'quite different concepts' of regionalism: regional cooperation, regional provision of public goods and services, and regional integration. They suggested that even though there were costs and benefits attached to moving from regional cooperation to either of the other two forms of regionalism, 'In the Pacific, regional approaches to overcoming capacity limitations in service delivery at a national level, and increasing economic opportunities through market integration are expected to provide the highest gains' (Final Draft 2005: 5). In order to fulfil this regional shift, the plan 'identifies 
a wide range of regional initiatives', which are listed under four key areas: economic growth, sustainable development, good governance and regional security. The plan puts forward 15 strategic objectives, which range from free trade to enhanced policing to the development of national sustainable development plans and a regional ombudsman's office. But before looking briefly at the content of the plan and its treatment of cultural identity in the strategic objectives and accompanying initiatives, it is useful to say a few words about the plan process.

\section{The process}

It should first be noted that there has not been extensive debate about the purpose, range and forms regionalism should take in the future in spite of the plan's consultation process. The EPG review consultations that were carried out in 2003 focused primarily on re-examining the role of the forum. The specific outcomes of the EPG review, as stated in its terms of reference, were 'a refreshed mandate and vision for the Pacific Islands Forum and an improved capacity within the Forum that allows it to provide leadership to the region on regional cooperation and integration' (EPG 2004: 58). While the idea of a Pacific Plan for greater regional cooperation grew out of that review, the process of consultation for the review did not focus on what sort or the extent of regionalism the peoples of the region aspire to. In addition, even though the EPG did consult with a variety of groups and institutions, the process was rushed, with the review team having less than a month to meet people face to face.

The initial draft Pacific Plan, dated December 2004 and put together by the Plan Task Force, was made available for national and regional consultations held in all countries of the region. But because the draft itself made assumptions about the benefits of regionalism (initiatives were presented under three time lines: early practical, medium-term and longer-term benefits), it might have pre-empted a debate about the benefits and costs of moving from one form of regionalism to another. Understandably, the authors of the draft were keen to set a framework for discussions, but, as a result, questions such as who currently benefits from regionalism, in what ways, whose interests regionalism serves, what sort of regionalism would benefit which countries (according to size, population, resources, etc.), and what sort of region is envisaged in 10 years and 20 years, were not widely asked, far less answered. Yet they were to some extent raised in the Toward a New Pacific Regionalism report that the Task Force used in framing the various drafts. Unfortunately, the way the drafts were designed and the way the plan now stands are not conducive to asking or answering these fundamental questions before moving on to practical initiatives. The plan process should have provided an opportunity for a thorough stocktake of regionalism and allowed for the development of a clear vision through a longer and more widespread consultation process. 
These important questions about the raison d'être and finality of regionalism as well as its possible forms tie in directly to the question of cultural identity at the regional level. This was recognised in the terms of reference of the Task Force, which stated that one of the issues the Task Force should consider was: 'A practical definition of a Pacific regional approach (i.e., a definition of "regionality") noting Leaders' declaration on the importance of maintaining and strengthening Pacific cultural identity.' However, defining 'regionality' with a strong focus on cultural identity was eschewed by the Task Force. This, in combination with the lack of widespread consultation during the drafting phase of the plan, has led to questions about the plan's suitability for the region, an aspect that is discussed in some of the plan submissions by regional civil society organisations.

\section{The content of the plan and culture}

The successive drafts of the plan have addressed culture essentially as a technical issue to be addressed through initiatives proposed under two of the four areas of economic growth, sustainable development, good governance and security. In the first draft, written in December 2004, culture appeared only as a component of sustainable development (in the medium-term benefit column) under the enigmatic description: 'Development of a regional plan to maintain and strengthen Pacific cultural identity through regional agencies, including relevant studies.' The draft gave no place to culture in the other priority areas. It was not mentioned as an asset either under economic growth or security. Under the good governance goal, reference to culture was made only indirectly in the proposed 'development of a regional approach to, and training in alternative dispute/conflict resolution as a cost effective alternative to the adversarial system'.

The plan identifies the strategic objective 'Recognise and protect cultural values, identities and traditional knowledge' under the sustainable development goal and proposes two specific initiatives for the first three years (2006-08): 1) 'Develop a strategy to maintain and strengthen Pacific cultural identity' (which appears under the 'agree in principle' category), and 2) 'Create an institution to advocate for and protect traditional knowledge and intellectual property rights' (under the 'further analysis' category). It also lists the following initiative under the good governance goal: 'Enhance governance mechanisms, including in resource management, and in the harmonization of traditional and modern values and structures.' This is listed in the implementation phase and the activity consists of 'support [for] the close coordination of existing initiatives including the USP's Pacific Institute of Advanced Studies in Development and Governance' (Final Draft 2005: 17).

According to an Issues Paper on 'Culture and the Pacific Plan' drafted by the Pacific Plan Office at the Forum Secretariat, culture is also earmarked to be 
considered in other plan initiatives, including in the assessment of the impacts of PACER and Free Trade Agreements for the region; support for the private sector; formulation and implementation of National Sustainable Development Strategies; upgrading of statistical information systems and databases; and implementation of a regional tourism marketing and investment plan.

Although this might appear to address the 'issue' of culture, it does not answer the question of formulating a 'practical definition of a Pacific regional approach'. The plan does not say what a Pacific regional approach is; it merely suggests what different forms of regionalism are possible (cooperation, regional provision of public goods and services and integration) and presents a list of initiatives to achieve further integration. In other words, it does not say anything about what is 'Pacific' about the plan other than its geographic focus.

\section{Making culture central to the plan: building on the past}

Is culture really important to regionalism in the Pacific? The track record of regional cooperation suggests that it is. In its review, the EPG wrote that the Pacific Way, 'however much it evolves to meet the demands of a changing world ... will have at its core one unchanging truth: regional interconnectedness, the idea that there is a Pacific way of doing things that is open to, but different from, the way Americans or Europeans or Asians might do things' (EPG 2004: 14).

The Pacific Way was at the heart of the Pacific Islands' initial engagement in regionalism, even though that engagement was driven mainly by the security concerns of the metropolitan powers in the aftermath of World War II. For many years, the concept of the 'Pacific Way' was used by Pacific Island states to define and differentiate themselves from other developing countries and regions of the world. Coined at the UN in 1970 by Ratu Sir Kamisese Mara, the then Prime Minister of Fiji, it came to symbolise a way of doing things specific to the Pacific: a way that emphasised moderation, respect, consensual dialogue, inclusiveness, as well as 'preparedness to negotiate, flexibility, adaptation and compromise'. It reflected a constructed regional consciousness as well as a gradual approach to modernisation and development. And for island leaders it symbolised a new start based on the assertion of a pan-Pacific ideal. The Pacific Way ideology therefore became a tool for continued cooperation with metropolitan powers and a diplomatic device for maintaining Pacific protocol and approaches (based on harmony and pragmatism) in regional and international affairs. And its general message was that Pacific Island countries were willing to work together with metropolitan countries but that the latter should respect them and not confuse them with Africa or other developing regions.

Today the idea of the Pacific Way is in need of a facelift. As the EPG admits: 'The Pacific Way is one of the region's greatest assets, but the concept must evolve and be reasserted if it is to remain relevant.' As an ideal, the Pacific Way 
has been damaged by political changes and, in some cases, crises, which have taken place in many of the Pacific Island countries (Fiji's coups in 1987 and 2000 have no doubt caused damage to the concept). It also has not been given sufficient substance even though the EPG tries to do so: 'In our view, this concept or style - which is often mentioned but seldom defined - implies honesty, mutual respect and tolerance. It is based on recognition and acceptance of differences, but with an underlying awareness of the need to find unity and consensus. The Pacific Way is guided by a sense of justice, compassion, tolerance and understanding. It is about working together' (EPG 2004: 20).

Now might be a good time to build on the Pacific Way as defined above and used by Pacific leaders for some 20 years, with the objective of defining a Pacific 'regionality' in which Pacific values, concepts and practices become the foundation for further cooperation. This approach is substantially different from including culture and cultural identity as mere token gestures. As Ron Crocombe warns with reference to the current plan process, it is no use highlighting culture only to undermine it through contradictory measures: 'The leaders emphasize the value they place on the strengthening of Pacific Islands languages and cultures. There are however, potential conflicts between some parts of the documents and others. Double-talk helps no one in the long run. Pacific cultures and languages are to be "strengthened", traditions and cultures are to be "honoured and developed". But many other aspects of the documents ensure they will be weakened and marginalized' (Crocombe 2005: 300).

This paper advocates placing Pacific values at the core of regionalism and building on cultural identity to give regionalism meaning and coherence. As Crocombe reminds us, there are 'two main bases to effective regional organizations anywhere in the world':

1. Material interactions: trade, investment, free movement of people, etc. For the Pacific Island region, these are very low, and account for only a small proportion of the total for almost any country.

2. Identity factors. It is in this area that Pacific Island regionalism has greater strengths — including feelings of common origins and historical experiences, common elements in value systems, cultural patterns and symbolic representation.

He goes on to explain that the identity factors are particularly important in the region:

In most of the world's regional organizations both material and identity factors are strong. In the Pacific Islands, however, it is unlikely that the material factors will grow significantly. If regional cooperation is to be promoted, therefore, more emphasis needs to be given to the identity factors. (Crocombe 2004: 300). 
At present, the plan misses the points made by Crocombe and the EPG review, namely that cultural identity is what links Pacific peoples, is an all-encompassing feature of life in the Pacific and is what peoples throughout the region have in common. Culture is viewed as an asset; it is a 'renewed source of wealth', of confidence and sustenance, even if it does pose many challenges and is complex to grasp. Addressing culture within the Plan by cutting it up into compartmentalised categories such as good governance and sustainable development rather than making it the foundation of the plan is a mismatched approach.

\section{The difficulties of integrating culture}

There are three interrelated reasons why it has been so difficult to make cultural identity an integral part of regional governance (beyond the rhetorical level) and the Pacific Plan: lack of political will and leadership, and pressure; lack of available conceptual tools to integrate culture into practical economic and political measures; and lack of understanding of what kinds of benefits could result from integrating cultural identity into a formal high-level regional plan of action.

Although Pacific Island leaders have spoken consistently about the need to better incorporate cultural values and norms in development and governance in the region, they have not made it a priority when it comes to implementation. One reason for this might be domination of the forum by countries or leaders who do not see Pacific culture, with its emphasis on solidarity and networks rather than competition and individual pursuit, as viable or beneficial for the region's development. Another is the lack of political leadership in regional affairs in the past 10 to 15 years, a period during which, as reported by the EPG, decisions have been formulated increasingly by officials rather than leaders, with the expectation that leaders will simply approve.

In addition to the lack of political direction, there is no doubt a lack of conceptual tools for integrating culture into existing political and economic frameworks (as well as a lack of will to develop them). There has been little research or strategic thinking about how to devise ways for the formal economy and political institutions to work hand in hand with communal structures and resource ownership, and to take advantage of community 'networking'.

There has been little effort in the region to understand how communities can utilise their human and cultural resources to enhance livelihoods while participating in the market economy. Advocates of the market economy assume that it will provide answers and that people will adapt to it - they do not envision another more appropriate solution, which is that the market should adapt itself to the social and cultural context. This is a more difficult task and involves some rethinking away from market and globalisation dogma, which asserts that globalisation is inescapable and that it is up to society to adapt to 
economic integration while conceding cultural, political and social disintegration. In its response to globalization, the region has thus far been reluctant (or has found it difficult) to go beyond declarations about the importance of people and culture into developing strategies for implementation.

\section{Culture and regionalism: a strategy}

There are three interrelated levels through which culture can be made central to the Pacific Plan. The first level is that of guiding principles; the second is that of a governance framework for the region and the plan; and the third level is that of strategic objectives or practical initiatives.

As Crocombe points out, 'basic to any culture is its value system'. He adds, however, that value systems vary within Pacific cultures (Crocombe 2005: 302). It is undeniable that there is real cultural diversity in the Pacific, but there are also many common values and similar practices. This is what Pacific leaders have been alluding to for many years in their references to the Pacific Way and to Pacific values. Although it is the role of the leaders and peoples of the region to agree on the predominant values together, we could suggest here, based on research already conducted by regional scholars and thinkers, that common values in the Pacific revolve around concepts of solidarity and reciprocity; the fostering and maintenance of kinship networks and relationships; attachment to land and sea; respect and care for others; the upholding of human dignity; and consultation and shared leadership.

These values (and perhaps others yet to be defined) should be made the basis for the guiding principles of regionalism: in other words, all initiatives and processes should be measured against these values. Guiding principles/norms would therefore seek to ensure that Pacific values were enhanced or promoted by regional initiatives. This is a step beyond framing a vision, which, although it provides an indication of how the region views itself (or what it aspires to), does not imply any commitment. A set of guiding principles, on the other hand, would clearly outline the values that the region seeks to uphold. It would be the responsibility of all those involved in regional decision-making to assess whether regional initiatives respect the guiding principles.

In order to facilitate this, culture should be incorporated at a second level, through the rethinking of a governance framework, or, as Grynberg and his co-authors refer to it, through the development of a 'political track' for the region (ADB 2005: xxvi). A political track that is cognisant of culture would seek not to create new 'mega-institutions', which further bureaucratise and centralise regional decision-making, but rather provide the means for enhancing dialogue between communities and the region (understood as regional institutions and regional leadership), and bringing regionalism to local communities. 
How to do this was one of the questions raised in a report by William Sutherland and others entitled Strengthening Regional Cooperation through Enhanced Engagement with Civil Society. This report was based on a project that aimed to 'seek community views on whether and how regional co-operation could be strengthened through enhanced community engagement', in which two-day community dialogues were held in Suva, Lautoka, Apia and Honiara (Sutherland 2005: 6). Participants were asked to find strategies to increase community engagement in regionalism. Four forms of engagement were suggested: 'direct engagement' where 'community representatives ... engage directly with regional organizations'; 'engagement through Regional Representatives', that is, 'through representatives of national associations of community groups or through regional umbrella organizations'; 'engagement through Regional Liaison Units, i.e., 'the formation of "regional liaison units" through which the community could work"; and 'engagement through a Pacific parliament' (Sutherland 2005: 26-7).

Although our focus here is not on strengthening regional cooperation but on encouraging the region and its institutions to better integrate cultural norms and practices, the suggestions listed above provide some ideas about implementing a 'political track'. Which of these would be most likely to promote the valuing of cultural identity at the regional level? The simple answer for present purposes is: all or any of the above.

This is because the main objective would be that, whatever form of engagement is put forward, community voices, rather than solely those that are representative of the State, are heard directly. Any of the above suggestions can most likely help to achieve this if implemented with that objective in mind. If the purpose of regionalism is to enhance the lives of people, it must have the means to understand and connect directly with those people. In the Pacific, communities rather than the State are the regulatory agents of society. People are protected from the destructuring or disintegrating effects of the market in large part by their cultural values and practices, including emphasis on solidarity and reciprocity, attachment to land, and focus on obligations and duties to others. In many countries of the Pacific, the State has limited capacity to regulate the impact of globalisation and the market as well as limited legitimacy. The community is in large part responsible for making sure that economic imperatives do not overwhelm society, rather that they are framed within a social structure that moderates them. (This is not to deny that it is becoming increasingly difficult for communities to do this as demands for consumerism grow.)

Regionalism should also focus on developing state capacity. But if we agree that it is important for regionalism to promote cultural identity as well as a 'focus on people', as the EPG advocated, it is logical for regional institutions and processes to work directly with those who practice or live cultural identity. Regionalism should seek to work closely with the institutions that hold the most political 
legitimacy - and these are generally local communities. This concurs with one of the key findings in Sutherland's report that 'the community clearly wants regional organizations to be more engaged with them and not just through governments', and might also address the real and perceived inequalities in the spread of the benefits of regionalism. As Crocombe states: 'Despite a rhetoric of priority for the poor, and verbal commitment to the Millennium Development Goals, it appears that the benefits of regional activity have gone disproportionately to the urban privileged' (2005: 299).

The suggestion for liaison offices reasserts the idea that a 'physical presence' is important for the effectiveness of regionalism and the 'distribution of benefits'. It also ensures that regional institutions are more attuned to the range of contexts in the region. In Crocombe's words, 'A danger of too much centralization is that staff of regional organizations spend more time interacting with each other and less with people throughout the region they are intended to serve' (2005: 299).

The recommendations put forward in the Sutherland report address the logistical aspects of improved interaction between communities and the region, including regionalism: 'accord[ing] the community the same recognition given [to] the private sector'; 'help[ing] communities to form regional associations'; 'explor[ing] the establishment of Regional Liaison Units based in Forum Islands Countries'; and 'work[ing] towards a Pacific Parliament with direct community representation' (2005: 4). It remains to be seen which would be cost-effective in providing consistent and beneficial interaction between the 'people' and regionalism.

Apart from the 'logistics' of interaction there is also the question of modes of interaction. How regionalism engages with people at all levels is as important as the structures that are created. This concern was raised at the forum leaders' level in their expressed desire to spend more time in discussion and 'less in "ticking-off" large volumes of paperwork provided by ministers and officials'. As the EPG commented (based on experience), '[I]mpossibly long meeting agendas and an overload of paperwork militate against good decision-making' (EPG 2004: 11). Not only should 'the Pacific Islands Forum ... continue its tradition of decisions through consensus based on a fluid agenda of discussion' (Powell [2005] argues that 'because this process is consistent with the cultural norms of Islanders, the execution of decisions by the Forum [carries] a needed level of legitimacy'), but regionalism should extend this mode of interaction to other levels. This relates directly to the concept of talanoa that Sitiveni Halapua has theorised about and advocated. Halapua organised a series of high-level talanoa dialogues between political leaders in Fiji after the 2000 coup, applying principles of reconciliation, inclusion and respect for cultural traditions. Even though it is important to be able to come to decisions so that actions are implemented, it is imperative for leaders and people, including bureaucrats, to have the opportunity 
to reflect on the purpose of regional action. It is not enough to leave this to academics. In addition, as pointed out by Powell, Halapua and others, talanoa is a process suited to reflection and decision-making in the region.

The third level at which cultural identity could be promoted is through regional initiatives or 'strategic objectives'. Among the 15 strategic objectives listed in the final draft of the Pacific Plan, only one deals specifically with cultural identity: Strategic Objective 11 (under sustainable development), which is to '[r]ecognise and Protect cultural values, identities and traditional knowledge' (Final Draft 2005: 16). The associated initiatives and milestones are not very clear so it is difficult to judge their potential efficacy at this point. But clearly the importance of preventing bio-piracy and protecting indigenous knowledge are urgent.

Another initiative to favour cultural identity (in this case, fomenting a greater appreciation and sharing of pan-Pacific cultural identity) is to foster greater exchanges between people of the region. The FSM emphasised this aspect in its national consultation plan submission under a section entitled 'Building a regional identity'. In it, the FSM advocates free skilled labour movement in the region as well as the 'establishment of a system of short-term secondment and exchange of officials' among Pacific nations. Crocombe makes a similar suggestion: 'If regional integration is to succeed in the long term, more attention needs to be given to human mobility.' He goes on to make concrete suggestions about how to make this possible, including a 'regional identity card', 'professional mobility', 'dual citizenship', 'teacher, student and media exchanges', as well as a 'Pacific volunteer service'. As Crocombe points out, in the case of exchanges, most of these occur 'between countries of the Forum region and countries outside it, but do not exist [in the case of teacher, student and media exchanges] ... within the Forum Islands region'. The plan lists including 'temporary movement of labour' in the Pacific Island Countries Trade Agreement but this appears as a purely economic growth measure rather than as a wider initiative to foster cultural exchange, understanding and development.

Another area that requires more attention is acknowledgment of the role of cultural and social capital. The point here is not to instrumentalise culture but to consider it as a key component in the development of economic policy. In other words, the region should seriously consider how to adapt economic practices to cultural contexts rather than the reverse. The Pacific Plan Office briefly addresses this question in its Culture and the Pacific Plan Issues Paper, but it is difficult to understand what it is advocating:

In an environment focused on economic growth and trade, those interested in conserving culture attempt to justify support for the issue through analysis of the economic value it contributes to the economy. However, its real value may lie in the loss Pacific Islanders will face after it is gone, as the tangible aspects 
of culture that contribute to the economy [are] only a small part of the whole. On the other hand, the lack of concerted effort in the field of culture also means that commercialization and exploitation of traditional knowledge, flora and fauna is a missed opportunity to share in the income that can be derived from it.

Does this mean that addressing culture in economic terms should be limited to the area of 'commercialisation and exploitation of traditional knowledge, flora and fauna'? To view the 'tangible aspects of culture that contribute to the economy as only a small part of the whole' is somewhat perplexing. Culture is a whole, it is civilisation embodied in thought and action; the economy is but a part of culture and of life. At least that is how it is viewed in the Pacific (and by many people throughout the world, including leading economists such as Amartya Sen).

Putting the economy at the service of culture and of life and society perhaps requires a shift in thinking, and it might be difficult to list this as a 'strategic objective'. But an objective of the Pacific Plan should be to consider it as an all-encompassing, core issue, one that is at the heart and not the margins of governance, economic growth, sustainable development and security.

\section{Conclusion}

In conclusion, we might want to ask ourselves again: what is the final aim of Pacific regionalism? Should it be an expression of values or an expression of interests? The sensible answer is that it is about both, and yet in the Pacific Plan now adopted by the forum, interests clearly trump values. The interests the plan seeks to promote are those that serve primarily economic integration without considering the values of the people it represents.

This is in spite of the fact that leaders have traditionally viewed regionalism in a humane way, with the Pacific Way preserving a particular outlook on society and the world. The EPG reiterated this outlook in its assertion that the real strength of the region lies in the character of its people, who have demonstrated throughout their history a high level of resourcefulness and resilience'. This positive outlook on the capacity of the peoples of the region to find the solutions to their problems is indicated by the additional statement that '[w]e are well used to surviving, and eventually prospering, in the face of hardship, invasions and natural disasters' (EPG 2004: 18). The point here is not to advocate complacency but to indicate that regionalism plans must build on these strengths not attempt to replace or contravene them.

Pacific cultural values such as solidarity and reciprocity and respect for kinship networks need to become the guiding principles of Pacific regionalism; communities need to be given a direct voice in regional institutions, and human mobility among island states needs to be encouraged not only for economic reasons but as part of a project to enhance a sense of regional identity. Above 
all, moves towards regional economic integration need to be tested constantly against the criterion of whether or not they reflect Pacific cultural values, and whether they enhance community.

\section{References}

ADB. 2005. 'Towards a New Pacific Regionalism.' Pacific Studies Series. An Asian Development Bank-Commonwealth Secretariat Joint Report to the Pacific Islands Forum Secretariat.

Crocombe, R. 2005. International context and lessons from other regions. Report posted on the Pacific Plan web site, September.

EPG. 2004. Pacific Cooperation: Voices of the Region, The Eminent Persons' Group Review of the Pacific Islands Forum, April.

Lind, Christopher. 2001. 'Integration and Disintegration - Ethics, Economic Globalisation and the Island of Hope.' In World Council of Churches, Island of Hope: A Pacific Alternative to Economic Globalisation, Report of the Churches' Conference on Economic Globalisation - Island of Hope, Nadi, Fiji, August 12-18 2001. pp. 63-82.

Pacific Islands Forum Secretariat. 2005. Final Draft: A Pacific Plan for Strengthening Regional Cooperation and Integration. Pacific Islands Forum Secretariat, September.

Powell, P. T. 2005. “"Too Young to Marry": economic convergence and the case against the integration of Pacific states.' In Satish Chand (ed.), Pacific Island Regional Integration and Governance, Canberra: Asia Pacific Press. Downloadable from ANU E-Press.

Ratuva, S. 2005. Social Security in Fiji, Kiribati, Samoa, Solomon Islands and Vanuatu: Traditional Social Protection Systems in the Pacific - culture, customs and safety nets. August 2005. Suva, Fiji: International Labour Office.

Raulston Saul, John. 2005. The Collapse of Globalism and the Reinvention of the World. Viking.

Sutherland, W. with R. Robertson, M. Koloamatangi and T. Kabutaulaka. 2005. Strengthening Regional Cooperation through Enhanced Engagement with Civil Society. Suva: PIAS-DG, USP. 